\section{Qualidade de vida intraurbana: a retomada dos espaços abertos públicos como locais de convívio social}

Quality of intra-urban life: the resumption of public open spaces as places of social interaction

\section{André Souza Silva* Bárbara Trevisan Casagrande**}

*Doutor e Mestre pelo Programa de Pós-Graduação em Planejamento Urbano e Regional da Universidade Federal do Rio Grande do Sul. Arquiteto e Urbanista, Docente e Membro do Comitê Científico de Iniciação Científica na Universidade do Vale do Rio dos Sinos. Pesquisador e Consultor Ad Hoc no Conselho Nacional de Desenvolvimento Científico e Tecnológico. Editor assistente do periódico Arquiteturarevista, silandre@unisinos.br

${ }^{*}$ Cursa graduação em Arquitetura e Urbanismo na Universidade do Vale do Rio dos Sinos e atua como bolsista de iniciação científica junto a pesquisas do Mestrado Profissional em Arquitetura e Urbanismo, btrevisancasagrande@yahoo.com

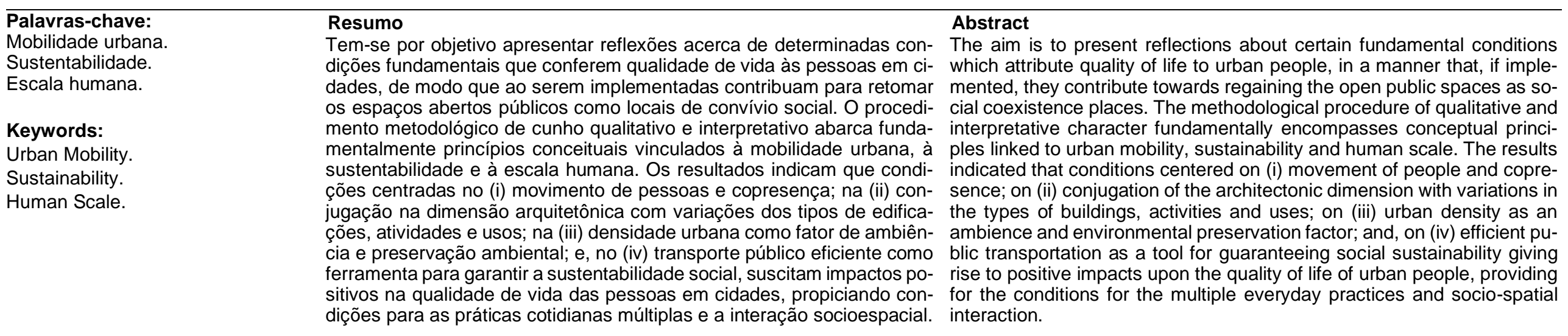

\section{usjt}

arq.urb

número 31 | mai-ago de 2021 Recebido: $10 / 09 / 2020$
Aceito: $19 / 07 / 2021$

DOI: $10.37916 /$ arq.urb.vi31.470

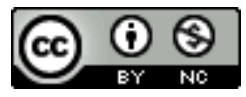
dições para as práticas cotidianas múltiplas e a interação socioespacial. 


\section{Introdução}

Atualmente, mais da metade da população mundial vive em áreas urbanas e este percentual tende a crescer consideravelmente nos próximos anos. No entanto, fazse necessário enfatizar que a ideia de crescimento está ligada a um viés quantitativo e o termo desenvolvimento apresenta característica qualitativa. Assim, uma cidade que cresce não necessariamente poderá ser entendida como desenvolvida já que as duas variáveis não são necessariamente proporcionais. É possível, por exemplo, que o desenvolvimento ocorra em uma cidade sem que haja alteração quantitativa dos índices populacionais ou de extensão territorial, evidenciando a inexistência de uma associação necessária entre os processos de crescimento e desenvolvimento urbano.

A realidade vista hoje, junto a algumas cidades brasileiras, é a presença de um elevado crescimento urbano, com aumento populacional e/ou expansão do uso do solo. Porém, esse processo não é acompanhado por uma manutenção da qualidade de vida da população, entendida como uma percepção individual pautada em aspectos de satisfação pessoal e bem-estar coletivo e relacionada com os padrões do ambiente em que se vive (BICHUETI, et al, 2019) não havendo, portanto, desenvolvimento considerável. Isso ocorre principalmente porque o rápido crescimento urbano e a falta de planejamento ocasionam frequentes problemas estruturais, tais como (i) carências em diversas áreas primordiais para a sociedade como a segurança; (ii) maiores níveis de poluição; (iii) incapacidade da infraestrutura das cidades em atender as necessidades geradas; e, (iv) dificuldade para as pessoas se deslocarem - especialmente entre suas moradias e seus locais de trabalho - constituindo uma deterioração da mobilidade urbana (REIS, 2014). Como resultante há a estruturação de espaços públicos destoantes com a escala humana e a consequente queda na qualidade de vida citadina (GEHL, 2013).

Portanto, o desenvolvimento se define pela existência de mudanças de estruturas a fim de gerar a melhora de indicadores econômicos e sociais, atrelado à sustentabilidade baseada na satisfação das necessidades de gerações presentes e futuras (BICHUETI, et al, 2019). Compreende um processo pelo qual ampliam-se as condições de execução dos direitos fundamentais, incluindo infraestrutura modal, recursos naturais, acessibilidade e lazer.
Diante disso, a problemática da pesquisa está centrada em quais condições qualitativas de mobilidade urbana, sustentabilidade e escala humana, são potenciais alternativas suscetíveis de produzir melhorias na qualidade de vida em áreas urbanas. A hipótese considerada é que a melhoria na qualidade de vida em áreas urbanas só será uma realidade na medida em que haja a elaboração de um modelo urbano que assegure o bem-estar das pessoas, entendido como a capacidade de viver considerando as dimensões materiais (como infraestrutura, habitação e serviços) e dimensões imateriais (como segurança, tranquilidade e felicidade) (GARCIAS, 2020).

Nesse contexto, alguns aspectos destacam-se como essenciais: (i) a mobilidade urbana de qualidade capaz de oferecer alternativas ao uso de automóveis; (ii) a sustentabilidade em torno da diminuição dos custos ambientais dos deslocamentos de pessoas e cargas no ambiente urbano; e, (iii) a atribuição da escala humana ao contexto urbano de modo a tornar os espaços abertos públicos aprazíveis e seguros. A partir desses princípios conceituais, advêm determinadas condições específicas, quais sejam: (i) movimento de pessoas e copresença; (ii) conjugação da dimensão arquitetônica com variações dos tipos de edificações, atividades e usos; (iii) densidade urbana como fator de ambiência e preservação ambiental; e, (iv) transporte público eficiente como ferramenta para garantir a sustentabilidade socioambiental.

Neste sentido, o objetivo desta pesquisa é apresentar reflexões conceituais acerca de determinadas condições que podem conferir qualidade de vida às pessoas em cidades, de modo que, ao serem implementadas, contribuam para retomar os espaços abertos públicos como locais de convívio social. A avaliação destes aspectos contribui para o diagnóstico das demandas públicas, pois envolve as necessárias mudanças qualitativas dos ambientes urbanos, bem como facilita o acompanhamento e análise dos resultados a partir da implementação de ações (ALVES, 2020).

Em termos metodológicos, a partir de conceitos e teorias dedutivas fundamentadas na revisão da literatura adotada, a pesquisa possui caráter qualitativo e interpretativo da realidade observada pelo pesquisador. Assim, os estudos utilizados para o embasamento dos debates propostos englobam análises referentes ao planejamento urbano e que investigam princípios capazes de potencializar as relações sociais e ampliar o sentido da cidade para todos, integrando-se aspectos humanos, 
ambientais e econômicos, sob enfoques qualitativos e quantitativos, considerando a relação entre indivíduo e meio (ALVES, 2020).

Os estudos metodológicos e conceituais analisados transparecem o ponto de contato entre ambientes, redes, sociabilidade e qualidade de vida urbana, muitas vezes associado à criação de espaços onde as pessoas se encontram, debatem e se unem como comunidade. Neste contexto, pode-se citar Jeff Speck (2012) e Douglas Farr (2013) que tratam da mobilidade urbana, Jan Gehl (2013) e Jane Jacobs (2000) que visam a escala humana, a vitalidade e a diversidade de usos e atividades, Andrei Crestani e Brenda Pontes (2016) que trazem a visão da copresença relacionada ao estabelecimento de múltiplas práticas cotidianas e TOD (Transit Oriented Development, 2013), com abordagem referente à densidade urbana.

\section{Convergência dos conceitos de mobilidade, sustentabilidade e escala hu- mana}

Sob o ponto de vista da qualidade de vida, as cidades podem ser analisadas a partir de princípios conceituais que envolvem a mobilidade urbana, a sustentabilidade ambiental e a escala humana, sendo que estes fazem parte de um todo inter-relacionado onde um princípio pode afetar positivamente ou negativamente os demais. Essa linha de pensamento deve ser empregada para compreender a realidade urbana brasileira com o objetivo de ressaltar suas potencialidades e/ou propor soluções a determinados aspectos que não se refletem em melhorias na escala dos espaços, nas soluções de mobilidade, na sustentabilidade, na segurança e na vitalidade das cidades.

A mobilidade está relacionada à facilidade com a qual as pessoas se deslocam em um determinado tecido urbano, sendo que a movimentação pela menor distância num menor dispêndio de tempo se relaciona com a existência de um planejamento urbano onde parte dos investimentos políticos e financeiros são destinados para o desenvolvimento de um sistema modal diversificado e de qualidade, que permita com que as pessoas tenham acesso às possiblidades e serviços que a cidade oferece (SPECK, 2012)

Segundo Marrara (2015, p. 123) a mobilidade urbana passa a ser entendida não como um fim em si mesma, mas como um meio essencial para que as pessoas satisfaçam suas necessidades de contato, fluxos e trocas, extraindo da cidade todos os benefícios que oferece à coletividade. No entanto, não basta apenas possibilitar o deslocamento das pessoas, mas também ter a presença de locais interessantes para atraí-las e tornar os espaços urbanos mais frequentados e seguros.

Tais fatores relacionam-se diretamente com a sustentabilidade ambiental já que a forma como a mobilidade é pensada para um ambiente urbano afeta as práticas diárias de deslocamento das pessoas, que optam pelo modo mais seguro e acessível, mas que pode não ser considerado o mais correto ecologicamente. O tipo de planejamento adotado em muitos centros urbanos brasileiros não contribui para incentivar a caminhabilidade e o desenvolvimento de um sistema eficiente de mobilidade, tornando o uso do veículo motor e individual o meio de transporte indispensável para satisfazer as necessidades diárias, tais como as vinculadas ao trabalho, lazer e moradia (FARR, 2013). Essa realidade tem reflexos sobre a sustentabilidade ambiental, já que os veículos de passeio e motocicletas possuem número limitado de passageiros se comparados a outros sistemas de transporte, como o ônibus, emitindo maior quantidade de poluentes per capita. $O$ desenvolvimento e incentivo ao uso de meios não motorizados, e consequentemente menos poluentes, requer infraestrutura que garanta a segurança e a qualidade da locomoção, existência de ciclovias e suportes urbanos para o deslocamento a pé (Figura 1).

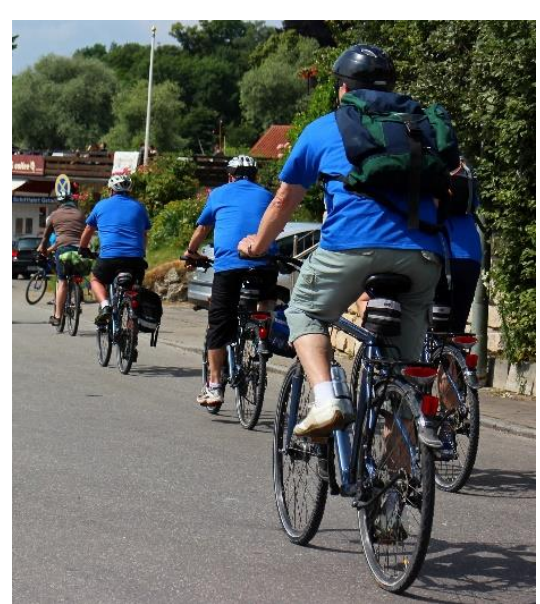

Figura 1: O desenvolvimento de uma cultura de uso da bicicleta e do deslocamento a pé, tornando-se práticas cotidianas em todos os grupos sociais. Disponível em: Pixabay - CCO Creative Commons. Acesso em: 13 jan. 2020. 
Como quesito complementar a tais aspectos, é possível trazer os conceitos de escala humana e copresença que estão vinculados a uma abordagem das cidades com foco na qualidade de vida das pessoas, fundamentada nas relações sociais percebida apenas na pequena escala, normalmente negligenciada nas propostas de planejamento urbano. A relação entre esses aspectos e a mobilidade é evidente nas características do espaço público, pois os padrões de deslocamento no tecido urbano influenciam diretamente nas propostas de urbanismo e nos parâmetros de velocidade empregados nas cidades, existindo diferenças marcantes em cidades projetadas para atender as demandas dos veículos motores e nas projetadas para atender as necessidades de quem se desloca a pé ou por meio de bicicletas. Consequentemente, isso também possui influência sobre a sustentabilidade porque uma cidade projetada para atender a escala humana torna-se mais segura e confortável para quem se locomove utilizando meios alternativos aos que emitem gases poluentes (GEHL, 2013). Desse modo, trabalhar com a escala das pessoas no planejamento de uma cidade afeta diretamente no modo como elas irão relacionar-se com os espaços abertos públicos e se estes serão locais propícios para a interação social.

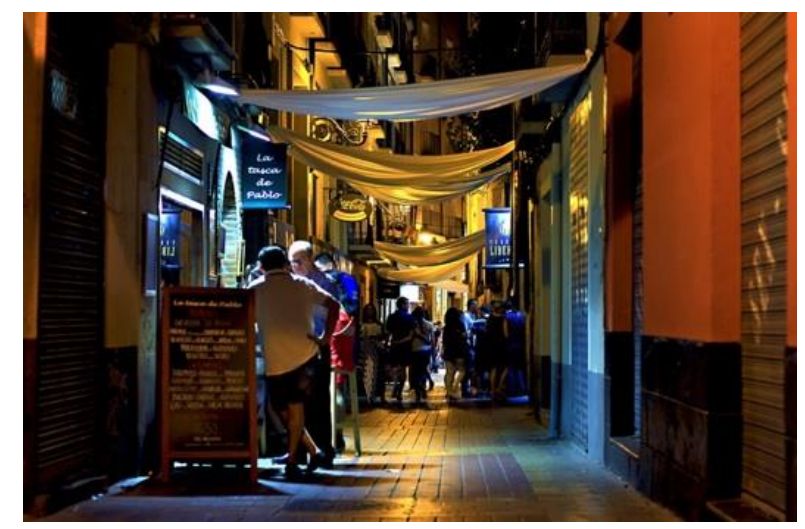

Figura 2: Cidades com vitalidade seguras e saudáveis estimulam experiências diretas entre as pessoas. Disponível em: Pixabay - CC0 Creative Commons. Acesso em: 3 mar. 2020.

Em muitas cidades brasileiras, o efeito criado pelo desenvolvimento urbano é a sua percepção como sendo pouco atraente para aqueles que não utilizam os veículos motores para a locomoção, minimizando, como consequência, o número de pessoas que optam por realizar trajetos através de meios alternativos. É preciso resgatar a vitalidade da rua, sendo impulsionada principalmente pela multiplicidade de pessoas, atividade e relações informais espontâneas (Figura 2).

A perda dessa diversidade é um reflexo das soluções urbanas generalizadas às grandes escalas, esvaziando do espaço público pedestres e, como consequência, sendo acompanhada pela sensação de insegurança nas cidades, já que as experiências cotidianas são cada vez mais marcadas pela indiferença e pela carência de interações sociais espontâneas e significativas que tornem o espaço público um local propício para o acesso e troca de informações. A perda da vitalidade pode levar as pessoas a não estabelecerem a sensação de apropriação fundamental em relação à cidade e a se locomoverem de automóvel com mais frequência, contribuindo também com níveis insatisfatórios de sustentabilidade ambiental (JACOBS, 2000).

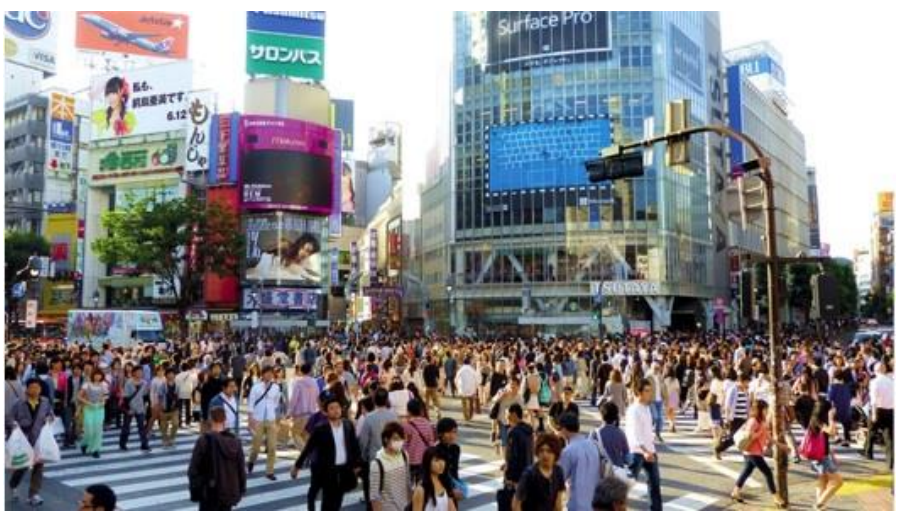

Figura 3: As múltiplas interações sociais no espaço urbano contribuem para difundir a sensação de segurança entre as pessoas e elevar a qualidade de vida nas cidades. Disponível em: Pixabay - CCO Creative Commons. Acesso em: 3 mar. 2020.

Nesse contexto, a ideia de copresença diz respeito ao modo pelo qual as cidades proporcionam o estabelecimento de múltiplas práticas cotidianas, onde as pessoas são atraídas a utilizar a rua e os espaços urbanos públicos e, consequentemente, a estabelecer uma dinâmica social demarcada pelas interações entre pessoas que partilham uma experiência comum com o mundo (CRESTANI; PONTES, 2016). 
Segundo Jane Jacobs (2000, p. 20) o "outro" aqui possui papel importante como sujeito que se integra ao total da experiência urbana e contribui para o estabelecimento de um certo sentimento inconsciente e solidário de confiança e segurança proveniente de uma série de contatos dos quais o espaço público é o cenário (Figura 3). Os frequentadores da rua extrapolam o seu papel como meros transeuntes e atuam como observadores (cuidadores) da cidade, motivando a confiança mútua e a sensação de proteção.

A partir dessas análises, é possível compreender as inter-relações existentes entre mobilidade urbana, sustentabilidade ambiental e escala humana, percebendo-se de que maneira o deslocamento através de veículos motores particulares promove consequências negativas ao meio ambiente com a emissão de grandes quantidades de poluentes, além de colocar o ciclista e o pedestre em posições desfavorecidas. Essa condição pode ser alterada a partir de um desenho urbano comprometido para reconhecer formas de mobilidade pouco valorizadas no Brasil.

Nessa circunstância, faz-se necessário propor bairros mais compactos e com alta densidade populacional e elaboração de zonas mistas, nas quais as edificações destinam os primeiros pavimentos a atividades ligadas ao comércio e ao serviço, enquanto que os demais pavimentos são reservados para habitações. Contemplase ainda a existência de ambientes públicos seguros que favoreçam a interação social entre as pessoas (TOD, 2013).

Como consequência, o desenvolvimento orientado implica um cenário urbano mais vibrante e caracterizado pelo uso do solo de modo a tornar mais conveniente e seguro caminhar, usar a bicicleta ou o transporte público. No entanto, é importante ressaltar que este sistema não pretende eliminar completamente o uso do automóvel privado, apenas que haja uma redução do tráfego nas vias públicas. Para tanto, são necessários investimentos para atrair as pessoas a utilizar outros meios de locomoção, tornando, por exemplo, as viagens através de transporte de massa mais curtas e rápidas. Outro fator importante é criar percursos de pedestres e ciclistas conectados aos diversos núcleos de interesse e de atração.

\section{Condições para atribuir qualidade de vida às pessoas em cidades}

Utilizou-se como pressupostos metodológicos quatro critérios conceituais relacionados à vitalidade das cidades e à concepção de ambientes adequados para as pessoas, onde a importância do domínio público é reconhecida para promover diversas atividades sociais. Dentre os critérios analisados estão o (i) movimento de pessoas e copresença; a (ii) conjugação na dimensão arquitetônica com variações dos tipos de edificações, atividades e usos; a (iii) densidade urbana como fator de ambiência e preservação ambiental; e, o (iv) transporte público eficiente como ferramenta para garantir a sustentabilidade social. A metodologia para elencar os critérios conceituais envolveu fundamentos do processo de investigação científica que contempla fatores considerados fundamentais para a existência de um cenário urbano mais dinâmico, a partir de diferentes escalas de entendimento, e caracterizado por ambientes públicos seguros que favoreçam a interação social (Tabela 1).

Foram abordados autores relacionados ao tema qualidade de vida nas cidades, sendo que Jeff Speck (2012) e Douglas Farr (2013) tratam da mobilidade urbana diversificada, otimizada e sustentável, como diretriz indispensável para que as pessoas tenham acesso às possiblidades e serviços que a cidade oferece. Também se agregam ao estudo os autores Jan Gehl (2013) e Jane Jacobs, 2000 que visam a escala humana, a vitalidade e a diversidade de usos e atividades como instrumentos necessários para o estabelecimento da sensação de apropriação fundamental em relação à cidade e à geração de interações sociais espontâneas e significativas que tornem o espaço público um local propício para o acesso e troca de informações. Em complemento, Andrei Crestani e Brenda Pontes (2016) trazem uma visão da ideia de copresença relacionada ao estabelecimento de múltiplas práticas cotidianas, segundo o qual as pessoas são atraídas a utilizar a rua e a estabelecer interações com outros indivíduos. A abordagem referente à densidade urbana adicionouse à discussão através do TOD (Transit Oriented Development, 2013) que contempla a existência de ambientes públicos seguros que favoreçam a interação social mediante à configuração de bairros mais compactos e com alta densidade populacional, aliado à elaboração de zonas de uso misto. Portanto, os aspectos fundamentais que norteiam a fundamentação da pesquisa compreendem princípios relacionados à mobilidade, sustentabilidade e escala humana sob o ponto de vista de princípios conceituais, embasando a posterior concepção das condições de qualidade de vida elencadas de modo específico e direcionado a temas pontuais.

Dentre os principais aspectos acerca dessa temática, pode-se citar a escala humana que significa, fundamentalmente, criar espaços adequados para pedestres, 
levando em consideração as possibilidades e limitações ditadas pelo corpo humano. O planejamento físico da cidade, envolvendo a preocupação com a escala empregada neste processo, pode influenciar no modo como as pessoas irão fazer uso dos espaços urbanos e nas escolhas de mobilidades diárias. $O$ fato de alguns lugares atraírem mais frequentadores que outros compreende um trabalho cuidadoso com a dimensão e com os sentidos humanos, sendo que diferentes organizações espaciais implicam em variações nas percepções sensoriais (GEHL, 2010).

Outro fator a ser analisado engloba a copresença, relacionada com a vitalidade do espaço público urbano e sua capacidade de influenciar as pessoas a não se limitarem a convivência na vida privada e, por consequência, serem atraídas a frequentar e explorar os ambientes da cidade por meio de movimentos que não se baseiam no uso do automóvel (JACOBS, 2000).

Na perspectiva de cidades com maior qualidade de vida para as pessoas, advém o aspecto referente à sustentabilidade ambiental no contexto dos centros urbanos, cuja diretriz procura atender às necessidades contemporâneas, considerando fatores econômicos, sociais e ambientais, visando proteger o patrimônio natural para gerações futuras (CMMAD, 1987). Em relação a este aspecto, a mobilidade tornase um item particularmente relevante porque é responsável por um consumo significativo de energia (FARR, 2013). Como alternativa a essa realidade deve-se priorizar o pedestre e a bicicleta, por meio de uma ampla política de tráfego com ênfase em sistemas modais alternativos, modificando o atual perfil do setor de transportes com a elevação da mobilidade para as pessoas e a redução do impacto sobre o meio ambiente (SPECK, 2012).

Importante considerar também o conceito de sustentabilidade social que busca difundir a todos os grupos da sociedade a oportunidade de se deslocar pelo tecido urbano de modo rápido e seguro. A igualdade é promovida pelo acesso às oportunidades que a cidade oferece à coletividade, tornando possível a liberdade de iniciativa, o direito ao lazer, à cultura e ao trabalho, além de gerar bem-estar às pessoas por meio do alcance aos serviços públicos sociais e econômicos. Essa realidade é incentivada quando há a possibilidade de uma vida cotidiana sem restrições impostas pela falta de opções de mobilidade ou pela impossibilidade de ter acesso a veículos particulares devendo-se, assim, incentivar a caminhabilidade e o uso de bicicletas, em combinação com o transporte público (GEHL, 2010).
Tabela 1: Fundamentação das condições que atribuem qualidade de vida às pessoas em cidades. Fonte: Elaboração própria (2020)

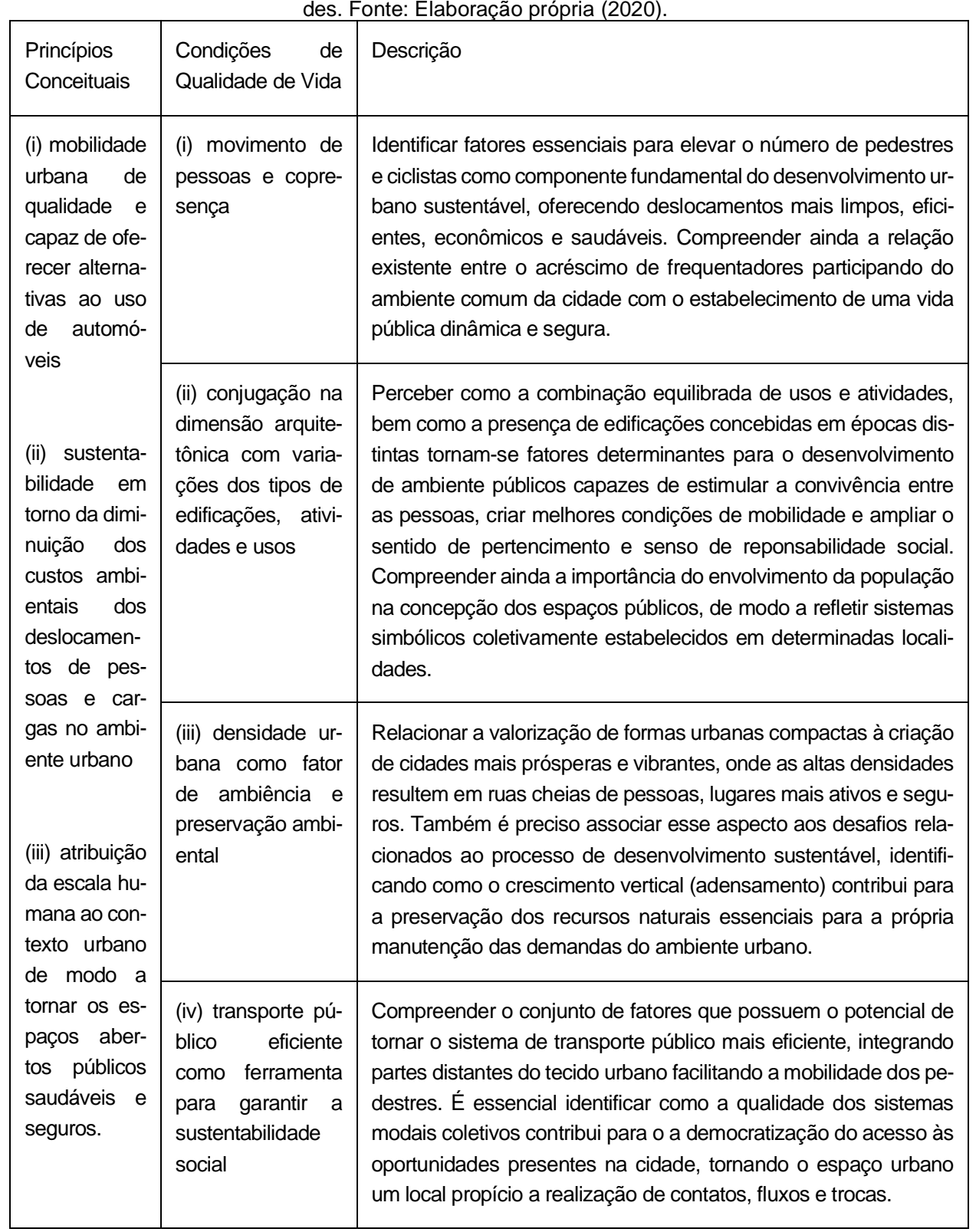




\section{Movimento de Pessoas e Copresença}

Caminhar é um componente fundamental da mobilidade sustentável porque oferece o deslocamento mais natural, econômico e saudável para curtas distâncias. No entanto, a fim de que mais pessoas optem por esse meio de locomoção alguns fatores são essências para tornar os trajetos mais gratificantes e produtivos. Um dos requisitos fundamentais de um ambiente urbano que estimule a caminhabilidade é a existência de ruas e vias ocupadas por outras pessoas, com calçadas povoadas, animadas e plenas de atividades e serviços, tornando o caminhar uma atividade segura e altamente produtiva. Para estimular isso, as fachadas ao nível da rua devem ser visualmente ativas, apresentando conexões visuais entre a calçada e o interior das edificações (Figura 4). Nesse contexto, Jan Gehl (2013, p. 41) discute o impacto do projeto das áreas térreas sobre a vida e o apelo do espaço urbano, afirmando que os pavimentos mais baixos devem ser agradáveis e ocupados por outras pessoas com o objetivo de elevar a atividade humana e evitar a sensação de insegurança e rejeição. De modo similar, as fachadas devem ser permeáveis, com conexões físicas ativas por meio de entradas e saídas de lojas, halls de edifícios, acesso a pátios, passagens e outras (TOD, 2013. p. 36).

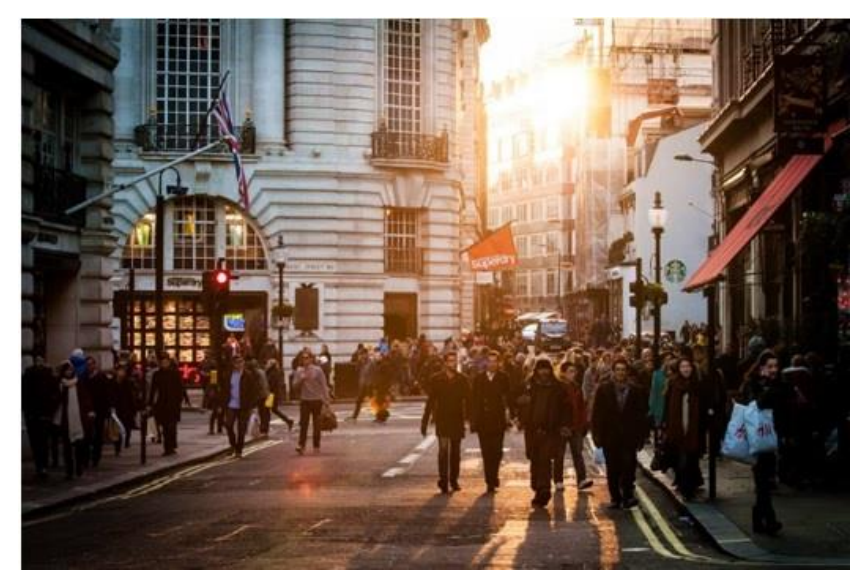

Figura 4: Ruas vibrantes, ocupadas por atividades humanas e com fachadas visualmente ativas e permeáveis contribuem para estimular a caminhabilidade e o uso da bicicleta. Disponível em: Pixabay - CC0 Creative Commons. Acesso em: 12 set. 2020.
Caminhar também demanda um certo esforço físico, sendo altamente sensível às condições ambientais. A disposição para caminhar pode ser elevada pela organização de elementos simples que tornem mais agradável o ambiente de pedestres, como a existência de árvores nas vias, fornecendo sombra, reduzindo a temperatura ambiente no calor, limitando o efeito do vento e absorvendo parte das emissões de escapamentos de veículos, além de elevar a taxa de permeabilidade do solo e melhorar a paisagem do ambiente urbano (PAIVA, 2018). Calçadas seguras e com dimensões confortáveis também devem ser consideradas como elementos importantes para estimular o movimento de pedestres, atendendo aos regulamentos de acessibilidade e contando com iluminação pública adequada.

Além do deslocamento a pé, a bicicleta é uma opção de transporte que contribui para a sustentabilidade ambiental, consumindo poucos recursos e sendo altamente eficiente, além de ser saudável e econômica. Assim como a caminhada, o uso da bicicleta é um componente necessário para complementar a maioria das viagens por transporte coletivo, onde as pessoas percorrem determinadas distâncias para acessar as estações ou outros serviços de mobilidade. $O$ tráfego de bicicletas deve ser integrado em uma proposta global com as outras redes de transporte, havendo a possibilidade de transportar esses veículos em trens, metrôs, táxis ou ônibus urbanos de modo que as viagens possam ser combinadas para percorrer distâncias maiores (HIGGINS, 2017).

Entretanto, os ciclistas estão entre os usuários mais vulneráveis das ruas e suas bicicletas frequentemente estão sujeitas a roubo e vandalismo. Para estimular o deslocamento através dessa forma alternativa é essencial oferecer condições atraentes para o uso da bicicleta, havendo mais segurança na circulação, no seu estacionamento e guarda, sendo necessários paraciclos disponíveis nos locais de destino e a possibilidade de armazenamento dos veículos em instalações privadas à noite ou em períodos mais longos. Outro fator essencial envolve a existência de uma rede de ciclovias segura e que conecte os principais destinos. De acordo com o Padrão de Qualidade TOD (2013, p. 20), vários tipos de ciclovias podem ser implementados com o objetivo de melhorar as condições para os ciclistas, incluindo pistas exclusivas, faixas de bicicletas nas vias e ruas que facilitam a sua circulação.

Segundo Douglas Farr (2013, p. 16), para priorizar os modos não motorizados é importante que seja criada uma rede altamente conectada de ruas e vias seguras, 
de modo a oferecer uma malha densa de múltiplas possibilidades de trajetos para se chegar a um destino e tornar as viagens a pé ou de bicicletas mais interessantes. Quadras pequenas e permeáveis também são interessantes, onde a maior frequência de esquinas e vias públicas mais estreitas geram fluxo veicular menos acelerado, elevando a sensação de segurança para ciclistas e pedestres (JACOBS, 2000). De acordo com o Padrão de Qualidade TOD (2013, p. 45) quadras com aproximadamente 110 metros de comprimento geram mais escolhas ao pedestre e ao ciclista e diferentes oportunidades para alterar seu trajeto e chegar ao endereço desejado, tornando o percurso interessante e diminuindo as distâncias entre os destinos.

Diante desse cenário, é importante ressaltar que a elevação no número de pedestres e ciclistas participando do espaço aberto público possui relação direta com o aumento da segurança nas cidades. De acordo com Jane Jacobs (2000, p. 20), a presença de outras pessoas indica que o local é bom e seguro e as pessoas passam a atuar como "olhos vigilantes", acompanhado o que acontece na rua e propiciando uma sensação reconfortante aos demais frequentadores, evitando traços de hostilidade e desconfiança. A ordem pública passa a ser mantida fundamentalmente por uma rede quase inconsciente de controles e padrões de comportamento aplicadas pelas pessoas presentes no ambiente comum da cidade, revelando um fenômeno de respeito e confiança mútuos (ADAM, 2008). O contato entre um maior número de pessoas na rua, apesar de aparentemente ser um fenômeno aleatório e despretensioso, constitui uma mudança significativa a partir da qual a vida pública tornase mais dinâmica e segura.

\section{Conjugação da dimensão arquitetônica com variações dos tipos de edifi- cações, atividades e usos}

A rede de espaços existentes entre as edificações da área urbana está associada à criação e ao fortalecimento de conexões humanas, manifestando a própria identidade de uma cidade como um campo de práticas cotidianas múltiplas (CACCIA, 2015). São responsáveis por moldar as relações comunitárias e sua apropriação contribui para desenvolver o sentido de pertencimento e o senso de responsabilidade, facilitando a mobilização social e estimulando diferentes ações das pessoas em prol do bem-estar comum (OLIVEIRA et al., 2010). Além destes, os espaços edificados e abertos às pessoas (por exemplo cafés, livrarias e bares), são propícios às interações e trocas sociais, encorajando encontros e impactando na qualidade de vida das cidades.

Para Jan Gehl (2013, p. 63) o espaço público possui a missão de refletir a diversidade e estimular a convivência entre as pessoas, criando condições para a permanência por meio da possibilidade de usufruir dos ambientes urbanos de diferentes modos. A combinação equilibrada de usos e atividades complementares em uma mesma quadra (ou quadras adjacentes), com a existência de edificações destinadas a múltiplas finalidades (residências, locais de trabalho e comércio local), favorece a ampliação da percepção de segurança e atratividade do ambiente comum (AGUIAR, 2012; PACHECO, 2010). Os usos diversos em horários de pico diferentes também contribuem para manter as ruas frequentadas por mais tempo, estimulando a atividade de pedestres em todos os turnos e conferindo uma elevação na qualidade e apropriação dos espaços públicos (TOD, 2013, p.23).

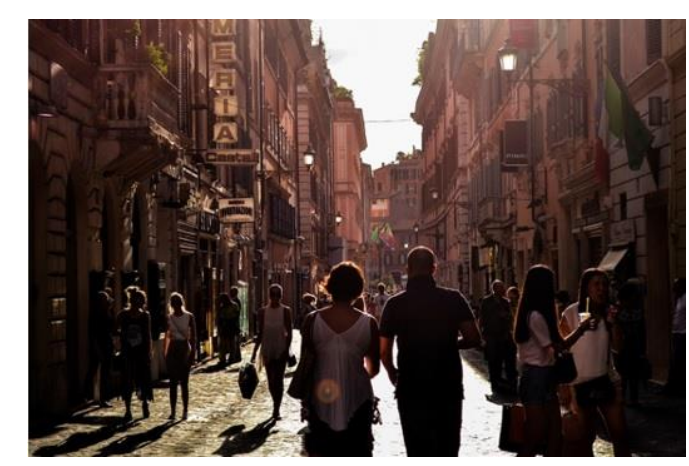

Figura 5: Espaço público como forma concreta de privilegiar encontros, interações e possibilidades de apropriação variadas, demarcado pela diversidade de usos e atividades. Fonte: Pixabay CC0 Creative Commons. Acesso em: 3 jan. 2020.

A manutenção da qualidade das áreas comuns da cidade requer o envolvimento das pessoas na sua concepção, planejamento e administração, de modo a considerar as dinâmicas sociais e as especificidades culturais de cada localidade. $O$ espaço urbano gerado pelas pessoas busca propiciar recursos para que estas adaptem infraestruturas existentes e criem ambientes com funções variadas que reflitam as demandas e desejos da população local, manifestando sistemas simbólicos 
coletivamente estabelecidos (SERPA, 2014) (Figura 5). A participação social é um fator determinante para a construção de áreas públicas seguras, equitativas e com uma identidade integrada à história da comunidade, gerando maior identificação entre as pessoas e o ambiente em que vivem (MOSTAFARI; DOHERTY, 2014).

Segundo Gordon Cullen (1983, p. 11) as condições favoráveis para que a cidade tenha qualidade urbana abrangem as experiências vivenciadas por meio da chamada "visão serial". Esta acontece quando as pessoas se deslocam pelas áreas comuns e deparam-se com novos ambientes, atividades e usos que surpreendem por sua diversidade e harmonia, configurando conjuntos de espaços que propiciam lugares de permanência, convívio e lazer. Nesse contexto, Jane Jacobs (2000) aponta a existência de usos combinados como um parâmetro para o bom desenvolvimento das cidades, tornando os lugares agradáveis, frequentados pelas pessoas e reforçando o senso de pertencimento.

Desse modo, Jane Jacobs (2000, p. 107) critica a cidade monofuncional e recomenda a mistura, não apenas de usos, mas também defende a existência de edificações concebidas em épocas distintas, com idades e estados de conservação variados como fator importante. Um grande espaço urbano construído em um mesmo período histórico pode apresentar degradação acentuada de modo simultâneo. A multiplicidade favorece ainda a existência de uma população não homogênea, com diversidade de renda dos ocupantes, onde as edificações novas tendem a apresentar maiores custos do que as antigas, que podem ser usadas pelas pessoas com menor poder aquisitivo, favorecendo a vitalidade da cidade e sua diversidade social. De acordo com o Padrão de Qualidade TOD (2013, p. 9), empreendimentos urbanos com renda mista contribuem para que mais pessoas permaneçam em espaços centrais da cidade e tornem-se potenciais usuários de sistemas modais alternativos ao uso dos veículos motores, satisfazendo suas necessidades diárias de deslocamento de maneira mais sustentável.

No entanto, em algumas cidades percebe-se que os diferentes usos tendem a ser mantidos separados, impossibilitando a mobilidade de forma rápida e com qualidade. A tendência ao zoneamento com a criação de áreas residências distantes e sem o equilíbrio adequado entre as atividades, resulta no estímulo para que muitas pessoas percorram extensos trajetos para acessar serviços básicos, recorrendo frequentemente ao uso do automóvel. Além disso, áreas de trabalho tendem a estar localizadas longe das moradias, inviabilizando o deslocamento a pé ou de bicicleta. Segundo Jeff Speck (2012, p. 210) empreendimentos urbanos que apresentam usos combinados contribuem para reduzir as distâncias das viagens diárias, permitindo que uma maior parcela dos trajetos seja realizada por meios alternativos ao uso de veículos motores.

\section{Densidade urbana como fator de ambiência e preservação ambiental}

A densidade populacional pode ser entendida como um dado estatístico que corresponde ao número de indivíduos de um determinado espaço geográfico pela unidade de superfície (ROGERS, 2013). Decisões tomadas nessa área possuem impacto significativo sobre a qualidade de vida no ambiente urbano, afetando a saúde pública, o meio ambiente, a produtividade nas cidades e os processos de convívios humanos como um todo (MASCARÓ, 1996). Por vezes, o crescimento urbano tende a intensificar consequências contrárias sobre o meio ambiente e sobre a população, restringindo gradativamente a qualidade de vida (GARCIAS, 2020). O Desenvolvimento Orientado ao Transporte (TOD) compreende uma proposta de crescimento urbano em formas compactas e densas, priorizando o crescimento vertical (adensamento) ao invés do crescimento horizontal (dispersão). O objetivo é criar cidades mais prósperas e sustentáveis, onde as altas densidades resultem em ruas cheias de pessoas, lugares mais ativos, vibrantes e seguros (Figura 6). Ainda segundo essa linha de pensamento, os únicos limites para a elevação nos índices de adensamento devem ser determinados pela ambiência dos espaços, preparados para o exercício das atividades humanas, havendo acesso a recursos naturais (luz solar e circulação do ar), acesso a espaços abertos públicos e proteção de recursos naturais, históricos e culturais (TOD, 2013, p. 24; BORIN, MEIRELES, 2020).

Para Jr. e Forbes Davidson (1998, p. 10) o crescimento das cidades relaciona-se com aspectos importantes referentes à sustentabilidade ambiental. $O$ desenvolvimento linear disperso e indefinido coloca em risco a preservação dos recursos naturais essenciais para a própria manutenção das demandas do ambiente urbano, havendo a necessidade de reformular a visão sobre a cidade e os padrões de urbanidade a fim de que o desenvolvimento ocorra de modo sustentável e duradouro (FILHO, et al., 2020; BRAGA, et al., 2020). Douglas Farr (2013, p. 19) também discute os benefícios das grandes densidades urbanas para a conservação do meio ambiente, afirmando que bairros mais densos e com ampla mistura de bens e 
serviços geram menos deslocamentos dependentes de automóveis e, por resultado, melhoram consideravelmente a qualidade de vida, minimizando os níveis de poluição.

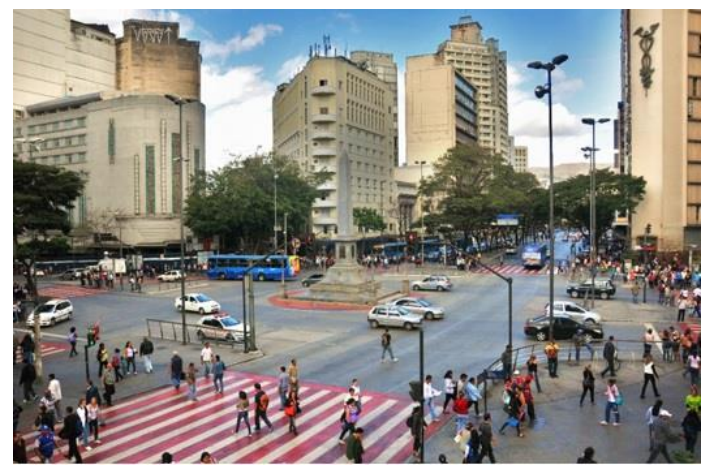

Figura 6: Densidades urbanas equilibradas contribuem para tornar as cidades mais vibrantes, com ruas frequentadas e seguras. Disponível em: Flickr - Domínio público. Acesso em: 3 abr. 2020.

De acordo com Graham Haughton e Colin Hunter (1994, p. 78) as densidades urbanas maiores beneficiam o desenvolvimento sustentável na medida em que há a maximização do uso das infraestruturas instaladas, diminuindo o custo de sua implantação e reduzindo a necessidade de sua expansão para espaços geográficos distantes. Os autores ainda afirmam que a concentração populacional é importante para estimular o pedestrianismo e viabilizar os serviços de transporte público, gerando maiores recursos para investimentos e melhorias na expansão do sistema. Além disso, há o estímulo ao surgimento de atividades econômicas, oferecendo a clientela de apoio para uma variedade de serviços ao nível local, diminuindo consequentemente a necessidade de realizar longas viagens para atender as necessidades diárias (TOD, 2013, p. 24).

Jane Jacobs (2000, p. 108) também apresentou discussões referentes a concentrações urbanas ideais. Segundo a autora a densidade suficientemente alta de pessoas é uma das condições essenciais para atribuir diversidade de usos às cidades, tornando as ruas mais movimentadas e reduzindo problemas como a criminalidade e o vandalismo. Ainda evidencia a relação entre concentração populacional e diversidade, onde os diferentes usos (trabalho, lazer e moradia) devem estar presentes no solo urbano a fim de contribuir efetivamente para as altas densidades e para promover a atratividade da cidade e a criação de infraestruturas eficientes (DEVECCHI, 2014; MASCARÓ, 1996).

Essa correspondência entre concentração populacional e diversidade contribui para apresentar um parâmetro que indica qual densidade urbana seria adequada para determinado espaço geográfico. A concentração populacional passa a ser algo negativo na medida em que afeta a funcionalidade da cidade, inibindo a existência de diversidade urbana em vez de a promover. Um exemplo disso é a padronização das construções, reduzindo as variações de idades e tipos, que estabelece relação direta com a decadência da diversidade populacional, de estabelecimentos e serviços (JACOBS, 2000). Dessa forma, é importante que o aumento do percentual da população ocorra com variações crescentes.

Cláudio Acioly Jr. e Forbes Davidson (1998, p. 42) destacam que, apesar de haver benefícios gerados por ambientes urbano com altas densidades em torno da maximização dos investimentos públicos e da utilização eficiente do solo disponível, é preciso ter cautela e realizar análises individuas dos espaços e suas necessidades. Assentamentos humanos com elevadas concentrações populacionais, quando concebidos sem o planejamento adequado, podem sobrecarregar as redes de infraestrutura e serviços urbanos e aumentar a pressão sobre o uso do solo. Para Juan L. Mascaró (1996, p. 24) as densidades urbanas ideais devem ser determinadas por meio de um estudo local, levando em conta os custos decorrentes da infraestrutura urbana (água, luz, esgoto e pavimentação), os custos da edificação (construção, terreno e capital) e os custos referentes a energia gasta para sua manutenção (elevadores, iluminação, refrigeração, entre outros). A taxa de adensamento urbano passaria a ser determinada de forma proporcional à infraestrutura instalada, estabelecendo-se um modelo capaz de garantir qualidade ambiental a um maior número de pessoas, oferecendo acesso à habitação, ao solo urbano e a equipamentos e serviços essenciais.

\section{Transporte público eficiente como ferramenta para garantir a sustentabili- dade social}

O transporte público possui a função de integrar partes distantes do tecido urbano e facilitar a mobilidade dos pedestres, podendo ser representado sob várias formas 
para viabilizar toda a gama de necessidades de deslocamento urbano, incluindo veículos de baixa e alta capacidade, estações de BRT (sistema de transporte de alta capacidade), metrô, táxis, ônibus articulados e trens (TOD, 2013, p. 22).

Para que as pessoas optem por utilizar o transporte público para a realização de atividades diárias, tais como as ligadas ao lazer, trabalho e à moradia, é preciso que determinadas ações sejam tomadas com o objetivo de tornar essa forma de mobilidade mais fácil e conveniente. Um fator importante em relação a isso refere-se à diminuição da distância máxima entre as pessoas e as estações de transporte público, de tal modo que esses serviços possam ser alcançados a uma curta distância a pé. De acordo com o Padrão de Qualidade TOD (2013, p. 30), a distância máxima recomendada à estação mais próxima de transporte de alta capacidade é de $1 \mathrm{~km}$, equivalente a uma caminhada de 15 a 20 minutos.

Em termos gerais, pode-se dizer que as pessoas que vivem em uma cidade querem ter acesso a tudo que ela oferece e, se grande parte dessas atividades e serviços não podem ser acessados convenientemente através do transporte público, quem possui condições financeiras irá adquirir um veículo particular (geralmente um carro) para satisfazer às suas necessidades (SPECK, 2012). Como consequência, as vias são alargadas e caminhar torna-se menos proveitoso, agradável e seguro. Esse efeito também contribui para diminuir o número de pessoas que optam por utilizar o transporte público visto que, com raras exceções, cada viagem por esse sistema modal começa e termina com uma caminhada. Desse modo, é importante compreender que o bom transporte público está intrinsecamente ligado à existência de projetos de intervenção que criem espaços urbanos de qualidade para o deslocamento a pé ou utilizando bicicleta, facilitando assim o acesso aos serviços de mobilidade.

Os sistemas de transporte público compreendem um importante mecanismo para o desenvolvimento urbano sustentável, conectando importantes destinos regionais, sendo que sua qualidade está relacionada à existência de uma política de planejamento de maneira conjunta ao estudo das densidades urbanas em determinado território. A concentração populacional em espaços geográficos próximos às estações de transporte público maximiza o número de pessoas aptas e dispostas a utilizar o serviço, contribuindo para que haja flexibilidade nos horários de funcionamento, variações de transportes ofertados e possibilidade de expansão dos sistemas modais para abranger maior quantidade de percursos compatíveis com as necessidades ligadas ao trabalho, moradia e lazer. A preparação para oferecer transporte público não deve ser feita de forma isolada no ambiente urbano, exigindo que ocorra sua implantação em locais com densidades urbanas adequadas para incentivar a expansão da infraestrutura de mobilidade (NOBRE, 2004).

Somando-se a isso, um dos principais incentivos para que as pessoas utilizem com mais frequência o transporte público urbano é a existência de serviço confiável no que diz respeito aos horários de chegada e partida, com certo conforto e eficácia cotidianamente, além de agregar valor ao tempo de deslocamento e proporcionar maior segurança aos passageiros. Tarifas justas e ampla cobertura da rede de transporte urbano também fazem parte desse conjunto de fatores que possuem o potencial de elevar a qualidade da mobilidade e de atingir a missão do serviço de transportes público como meio de proporcionar o acesso universal às oportunidades presentes na cidade, tais como a oferta de empregos, aprimoramento da carreira profissional, acesso à educação e a serviços básicos de saúde, aquisição de cultura geral, entre outros (SILVEIRAI; COCCOI, 2013).

Nesse contexto advém o conceito de sustentabilidade social com foco em criar oportunidades iguais para que todos os grupos da sociedade tenham acesso ao espaço público e também de se movimentar pela cidade (GEHL, 2013). A igualdade é incentivada ne medida em que as pessoas, mesmo não possuindo um veículo próprio, podem ter acesso as oportunidades que a cidade oferece através do deslocamento a pé e utilizando bicicleta, em conjunto a um sistema eficiente de transporte público.

Um importante fator pelo qual o ser humano se reúne em aglomerações urbanas envolve a possibilidade de realizar trocas com outras pessoas, compreendendo não apenas o intercâmbio de objetos, mas difundindo-se em um conceito mais amplo, havendo o fluxo de sentimentos, informações, culturas, salários e serviços (MARRARA, 2015). Para que o sentido do espaço urbano como local de contatos, fluxos e trocas ganhe uma amplitude democrática, difundindo-se a todos os grupos sociais, é essencial a existência de um sistema transporte público que garanta o deslocamento com facilidade, velocidade, segurança e a um custo acessível. 


\section{Considerações finais}

A qualidade de vida constitui um tema atual nos estudos sobre planejamento e gestão do espaço urbano, podendo ser entendida como a expressão utilizada para definir as particularidades das condições de vida das pessoas, considerando aspectos variados que permitem elevar o grau de satisfação e bem-estar físico e psíquico. Admitindo-se o rápido e contínuo crescimento das áreas urbanas brasileiras, temse um acúmulo de adversidades no que tange ao planejamento urbano e à consequente incompatibilidade com a manutenção da qualidade de vida. $O$ interesse $e$ preocupação manifestados em nível nacional por essa problemática têm intrinsecamente a necessidade de compreender quais são as condições determinantes para a avaliação e aperfeiçoamento das condições de habitabilidade das cidades. A proposição de alternativas capazes de atribuir qualidade de vida às pessoas deve abranger uma abordagem multisetorial, com discussões e análises que percorram as mais diversas dimensões do planejamento territorial.

Desde o ponto de vista do objetivo da pesquisa, o interesse deteve-se, por um lado, em apresentar reflexões acerca de determinadas condições fundamentais que, ao serem implementadas, possam contribuir para retomar os espaços abertos públicos como locais de convívio social; por outro, na questão centrada em quais condições qualitativas de mobilidade urbana, sustentabilidade e escala humana sejam alternativas potencialmente aptas a melhorar a qualidade de vida em áreas urbanas. A pesquisa contribui para a condição de elencar critérios conceituais que, por meio da revisão da literatura, apresentaram-se como fatores estruturais que suscitam condições para as práticas cotidianas múltiplas e a interação socioespacial, em específico o movimento de pessoas e a copresença que, juntamente com o transporte público eficiente, estão em conjugação com a dimensão arquitetônica, a partir das densidades construídas e das variações dos tipos de edificações, atividades e usos.

A partir dos procedimentos metodológicos, pode-se delimitar princípios conceituais para analisar as cidades sob o ponto de vista da qualidade de vida que proporcionam às pessoas, identificando-se temas globais referentes à mobilidade urbana, sustentabilidade ambiental e escala humana empregada. Esses elementos constantemente são apontados pelos autores como essenciais para o embasamento de estudos referentes ao enfrentamento das contradições urbanas, referindo-se ao resgate do espaço urbano como local de encontros e reprodução da vida coletiva real.
Decorrente da reflexão acerca dos princípios conceituais analisados, pôde-se elencar determinadas condições em específico, consideradas decisivas para ampliar o sentido da qualidade de vida em cidades. Identificou-se como primeiro fator o movimento de pessoas a partir do desenvolvimento da cultura sustentável do uso da bicicleta e do deslocamento a pé através da organização de elementos simples que tornem os trajetos mais gratificantes, seguros e produtivos.

Foram verificadas relações entre diversidade e estimulo às interações sociais e o estabelecimento de combinação equilibrada de usos e atividades em uma mesma escala territorial, bem como a presença de edificações concebidas em épocas distintas, facilitando encontros e criando condições de permanência. Além disso, evidenciou-se a importância do urbanismo gerado pelas pessoas como ferramenta essencial para atender suas demandas e desejos e, como resultado, reforçar o senso de pertencimento em relação ao meio em que vivem.

Outro aspecto para alcançar o bem-estar social compreende a relação existente entre a valorização de formas urbanas compactas e a criação de cidades mais prósperas, vibrantes e sustentáveis. Constatou-se que as decisões tomadas nessa área impactam significativamente os níveis de satisfação das pessoas residentes no ambiente urbano, afetando a ambiência dos espaços, a proteção dos recursos naturais, a maximização dos investimentos públicos e a utilização eficiente do solo disponível.

Identificou-se ainda a importância do sistema de transporte público aliado a providências efetivas que tornem mais perene o cuidado com a mobilidade urbana. Destaca-se como importante mecanismo para o desenvolvimento urbano sustentável e para a integração de partes distantes do tecido urbano, facilitando a mobilidade dos pedestres e a democratização de acesso aos serviços e possibilidades que a cidade oferece à coletividade. 


\section{Referências}

ACIOLY, Claudio, DAVIDSON, Forbes. Densidade Urbana: Um Instrumento de Planejamento e Gestão Urbana. Rio de Janeiro: Mauad, 1998.

ADAM, Roberto Sabatella. Analisando o Conceito de Paisagem Urbana de Gordon Cullen. 2008. Disponível em: < https://estudanteuma.files.wordpress.com/2013/04/gordeon-cullen-cc3b3pia.pdf>. Acesso em: 12 jan. 2020.

AGUIAR, Douglas. Urbanidade e a qualidade da cidade. 2012. Disponível em: <https://www.vitruvius.com.br/revistas/read/arquitextos/12.141/4221>. Acesso em: 05 jan. 2020.

ALVES, Lidiane Aparecida. O que é e como alcançar a qualidade de vida?. 2020. Disponível em: <https://www.revistas.ufg.br/bgg/article/view/57699/34418>. Acesso em: 14 fev. 2021.

BICHUETI, Roberto Schoproni et al. Cidades Sustentáveis no Contexto Brasileiro: A Importância do Planejamento para o Desenvolvimento Urbano Sustentável. XIX ENGEMA. Santa Maria. 2019. Disponível em: <http://engemausp.submissao.com.br/19/anais/arquivos/113.pdf>. Acesso em 10 mai 2021.

BORIN, Camila Parachini F., MEIRELES, Eduardo. Arenas Urbanas: O capital na contramão das cidades sustentáveis. 2020. Disponível em: <https://www.brazilianjournals.com/index.php/BRJD/article/view/5978/5333>. Acesso em: 14 fev. 2021.

BRAGA, Cristiane Borges et al. Sistemas para avaliação de cidades inteligentes e sustentáveis: uma revisão bibliográfica. 2020. Disponível em: <https://amigosdanatureza.org.br/publicacoes/index.php/gerenciamento_de_cidades/arti-

cle/view/2437>. Acesso em: 14 fev. 2021.

CMMAD, Comissão Mundial sobre Meio Ambiente e Desenvolvimento. Report of the World Commission on Environment and Development: Our Common Future. 1987. Disponível em: <https://sustainabledevelopment.un.org/content/documents/5987our-common-future.pdf>. Acesso em: 13 fev. 2021.

CACCIA, Lara Schmitt. Mobilidade urbana: Políticas Públicas e apropriação do espaço em cidades brasileiras. 2015. Disponível em: <https://lume.ufrgs.br/handle/10183/133191>. Acesso em: 11 mar. 2020.
CRESTANI, Andrei, PONTES, Brenda Brandão. O espaço público (in)visível ao olhar de Jacobs. Revista Políticas Públicas \& Cidades. v.4, n.2, p.107 - 126. ago./dez. 2016. Disponível em: <https://www.researchgate.net/publication/315244929 O espaco publico invisivel ao olhar de Jacobs>. Acesso em: 11 fev. 2020.

CULLEN, Gordon. Paisagem urbana. 1983. Disponível em: <https://estudanteuma.files.wordpress.com/2015/05/cullen-gordon-paisagem-urbana.pdf>. Acesso em: 11 mar. 2020.

DEVECCHI, Alejandra Maria. Políticas de compactação urbana. 2014. Disponível em: <https://revistaarqurb.com.br/arqurb/article/view/283>. Acesso em: 3 fev. 2020.

FILHO, Edson Maia Villela et al. Inclusão da Infraestrutura Verde no Planejamento das Cidades. 2020. Disponível em: <http://cescage.com.br/revistas/index.php/RTE/article/view/1048/pdf>. Acesso em: 14 fev. 2021.

FARR, Douglas. Urbanismo Sustentável: Desenho Urbano com a Natureza. Porto Alegre: Bookman, 2013.

FREE-PHOTOS. 2012. Figura 4. Disponível em: <https://pixabay.com/pt/urbanaspessoas-multid\%C3\%A3o-cidad\%C3\%A3os-438393/>. Acesso em: 12 set. 2020.

GARCIAS, Carlos Mello et al. Proposta de um indicador de desenvolvimento sustentável com base na qualidade de vida, bem-estar e felicidade: estudo piloto na cidade de Curitiba, Brasil. 2020. Disponível em: <http://www.scielo.mec.pt/scielo.php?script=sci_arttext\&pid=S0003-25732020000100007 >. Acesso em: $14 \mathrm{fev}$. 2021.

GEHL, Jan. Cidade para Pessoas. São Paulo: Perspectiva, 2013.

GOH, Jason. 2013. Figura 3. Disponível em: <https://pixabay.com/pt/jap\%C3\%A3o†\%C3\%B3quio-shibuya-japon\%C3\%AAs-217882/>. Acesso em: 3 mar. 2020.

HAUGHTON, Graham, HUNTER, Colin. Sustainable cities. 1994. Disponível em: $<$ http://www.stellenboschheritage.co.za/wp-content/uploads/Sustainable-Cities.pdf>. Acesso em: 07 jan. 2020. 
HIGGINS, Hayden. Urban Biking Advice from Copenhagen, Portland and Beyond. 2017. Disponível em: <https://www.wri.org/blog/2017/01/urban-biking-advicecopenhagen-portland-and-beyond>. Acesso em: 20 fev. 2020.

JACOBS, Jane. Morte e vida de grandes cidades. 1. ed. São Paulo: Martins Fontes, 2000.

MARRARA, Thiago. Transporte Público e Desenvolvimento Urbano: Aspectos Jurídicos da Política Nacional de Mobilidade. 2015. Disponível em: <https://www.revistas.usp.br/rdda/article/viewFile/84691/92181>. Acesso em: 26 fev. 2020.

MASCARÓ, Juan Luís. Desenho e custos de infra-estrutura urbana. 2. ed. Porto Alegre: Sagra Luzzatto, 1996.

MERLIN, Pierre, CHOAY, Françoise. Dictionnaire de L'Urbanisme et de L'aménagement. Paris: Presses Universitaires de France, 1988. Disponível em: <https://doi.org/10.7202/022144ar>. Acesso em: 25 fev. 2020.

MOSTAFARI, Mohsen et al. Urbanismo Ecológico. São Paulo: Gustavo Gili, 2014.

NEBREDA, Daniel. 2017. Figura 2. Disponível em: <https://pixabay.com/pt/noite-bares-cidade-cadeiras-2467970/>. Acesso em: 3 mar. 2020.

NOBRE, Eduardo. A. C. Desenvolvimento Urbano e Sustentabilidade: Uma Reflexão sobre a Grade de São Paulo no Começo do Século XXI. 2004. Disponível em: $<$ http://labhab.fau.usp.br/biblioteca/textos/nobre desenvolvimento urbano sustentabilidade.pdf $>$. Acesso em: 3 fev. 2020.

OLIVEIRA, Marília Flores Seixas de et al. Mobilidade Urbana e Sustentabilidade. 2010. Disponível em: <http://anppas.org.br/encontro5/cd/artigos/GT11-236-94920100904103333.pdf $>$. Acesso em: 11 ago. 2020.

PACHECO, Priscila et al. Espaços Públicos: 10 princípios para conectar as pessoas e a rua. 2010. Disponível em: <http://thecityfixbrasil.com/2017/06/07/espacos-publicos-10-principios-para-conectar-as-pessoas-e-a-rual>. Acesso em: 11 fev. 2020.

PAIVA, Lincoln. Afastar pedras do caminho e plantar árvores no asfalto. 2018. Disponível em: <http://www.vitruvius.com.br/revistas/read/minhacidade/18.212/6919>. Acesso em: 2 jan. 2020.
PATARO, Breno. Personagens e histórias povoam as esquinas da Praça Sete. 2012. Figura 6. Disponível em: <https://www.flickr.com/photos/portalpbh/8202888805/>. Acesso em: 3 abr. 2020.

REIS, Manoel. Mobilidade Urbana: Um Desafio para Gestores Públicos. 2014. Disponível em: <http://bibliotecadigital.fgv.br/dspace/bitstream/handle/10438/16446/cidades inteligentes e mobilidade urbana 0.pdf? sequence $=1$ \&isAllowed $=\mathrm{y}>$.

Acesso em: 26 fev. 2020.

ROGERS, Richard. Cidades para um pequeno planeta. 1. ed. $6^{\underline{a}}$ reimpressão. São Paulo: G. Gili, 2013

SERPA, Angelo. Teoria das representações em Henri Lefebvre: por uma abordagem cultural e multidimensional da geografia. 2014. Disponível em: $<$ https://www.revistas.usp.br/geousp/article/download/83538/92874>. Acesso em: 18 mar. 2020.

SILVEIRAI, Márcio Rogério, COCCO, Rodrigo Giraldi. Transporte público, mobilidade e planejamento urbano: contradições essenciais. 2013. Disponível em: $<$ http://www.scielo.br/pdf/ea/v27n79/v27n79a04.pdf>. Acesso em 18 mar. 2020.

STOCKSNAP. 2017. Figura 5. Disponível em: <https://pixabay.com/pt/homem-mulher-pessoas-turistas-2616599/>. Acesso em: 3 jan. 2020.

SPECK, Jeff. Cidade caminhável. São Paulo: Perspectiva, 2012.

TOD, Transit Oriented Development. Rio de Janeiro: ITPD, 2013.

ZIMMER, Manfred Antranias. 2014. Figura 1. Disponível em: <https://pixabay.com/pt/photos/lazer-recupera\%c3\%a7\%c3\%a3o-f\%c3\%a9rias-ciclistas374492/>. Acesso em: 13 jan. 2020. 